\title{
Venous thromboembolism: current management
}

\section{SUMMARY}

Anticoagulation is indicated in most cases of venous thromboembolism.

Monotherapy with rivaroxaban or apixaban is the preferred option for most adults with acute venous thromboembolism.

There are no recommended dose reductions for rivaroxaban or apixaban in venous thromboembolism, unlike for atrial fibrillation.

The initial duration of anticoagulation is usually three months.

Extended treatment with low-dose rivaroxaban or apixaban is effective in preventing recurrence in patients with a continuing increased risk of thromboembolism. Both drugs have low rates of major bleeding.

\section{Introduction}

Therapy for venous thromboembolism traditionally involved parenteral anticoagulation and subsequent warfarin. However, this approach has changed with the introduction of the direct oral anticoagulants:

- rivaroxaban and apixaban (factor Xa inhibitors)

- dabigatran (direct thrombin inhibitor).

Venous thromboembolism can present as deep vein thrombosis or pulmonary embolism. It has an incidence of about 1.5 in 1000 people per year and a lifetime prevalence of more than $5 \%$. $^{1}$ The diagnosis requires urgent assessment. Anticoagulation is usually needed to reduce the risk of fatal pulmonary embolism and morbidity from recurrent venous thromboembolism, post-thrombotic syndrome and pulmonary hypertension. ${ }^{2,3}$

When compared with warfarin, direct oral anticoagulants are as effective in preventing recurrent venous thromboembolism, and have a strong trend to less bleeding. They also have the advantage of having few food and drug interactions and do not require laboratory monitoring..$^{4-7}$ Apixaban and rivaroxaban can be used as monotherapy and are now the preferred option for most adults with acute venous thromboembolism.

\section{Before considering anticoagulation}

All patients require a full blood count, biochemical analysis and coagulation studies. Pregnancy should be excluded in women of childbearing age. ${ }^{8}$ Testing for thrombophilias, such as the factor $\mathrm{V}$ Leiden and prothrombin gene mutations, is generally unhelpful as the presence of these abnormalities has little influence on the risk of recurrent venous thromboembolism and therefore on determining the duration of anticoagulation. It is reasonable to test for the antiphospholipid antibody syndrome in patients with unprovoked venous thromboembolism who are under 45 years of age.

Drug interactions with direct oral anticoagulants are infrequent. However drugs that significantly alter the function of P-glycoprotein (including azole antifungals, rifampicin, amiodarone or quinidine) or cytochrome P450 3A4 (including HIV protease inhibitors, clarithromycin, carbamazepine and rifampicin) $)^{9,10}$ may influence their anticoagulant effect. Seek a specialist opinion for patients taking any of these medicines.

\section{Initial anticoagulation}

Most patients can be started on monotherapy with rivaroxaban or apixaban without the use of parenteral anticoagulant therapy. After an initial period of more intense oral anticoagulation, therapy is reduced to maintenance dosing (see Table 1).

\section{Table 1 Dosing schedule for rivaroxaban and apixaban in venous thromboembolism}

\begin{tabular}{llll} 
Drug & Initial phase & $\begin{array}{l}\text { Maintenance phase } \\
\text { up to six months }\end{array}$ & $\begin{array}{l}\text { Renal } \\
\text { contraindication }\end{array}$ \\
\hline Rivaroxaban & $\begin{array}{l}15 \mathrm{mg} \text { twice daily } \\
\text { for } 21 \text { days }\end{array}$ & $20 \mathrm{mg}$ once daily & $\mathrm{CrCl}^{*}<30 \mathrm{~mL} / \mathrm{min}$ \\
\hline Apixaban & $\begin{array}{l}10 \mathrm{mg} \text { twice daily } \\
\text { for } 7 \text { days }\end{array}$ & $5 \mathrm{mg}$ twice daily & $\mathrm{CrCl}^{*}<25 \mathrm{~mL} / \mathrm{min}$ \\
\hline
\end{tabular}

* calculated creatinine clearance $(\mathrm{CrCl})$ based on the Cockroft-Gault formula 
Correct dosing of both the initial period and maintenance treatment is extremely important to ensure efficacy. There is no dose reduction based on age, low weight or moderate renal impairment with rivaroxaban and apixaban, in contrast to their use in atrial fibrillation. However, they are contraindicated in severe renal impairment (creatinine clearance below $30 \mathrm{~mL} / \mathrm{min}$ ).

Dabigatran is approved for the treatment of venous thromboembolism, but is not currently subsidised through the Pharmaceutical Benefits Scheme for this indication. Unlike rivaroxaban and apixaban, a parenteral anticoagulant (e.g. enoxaparin) needs to be used for five days before starting dabigatran. As dabigatran is predominantly eliminated via the kidneys, it is contraindicated in severe renal impairment. ${ }^{9}$

\section{Which anticoagulant is best for my patient?}

Rivaroxaban or apixaban are generally favoured over dabigatran or warfarin as they do not require a period of parenteral anticoagulation or routine laboratory monitoring (see Fig.). However, there are several circumstances in which a heparin overlapping with warfarin remains the standard of care. These include:

- $\quad$ severe chronic kidney disease (CKD stages 4 or 5)

- extremes of body weight ( $\leq 50 \mathrm{~kg}$ or $\geq 120 \mathrm{~kg}$ )

- $\quad$ antiphospholipid antibody syndrome."

All oral anticoagulants are contraindicated in pregnancy. A low-molecular-weight heparin, such as enoxaparin or dalteparin, remains the standard of care.

\section{Fig. Initial treatment of venous thromboembolism}

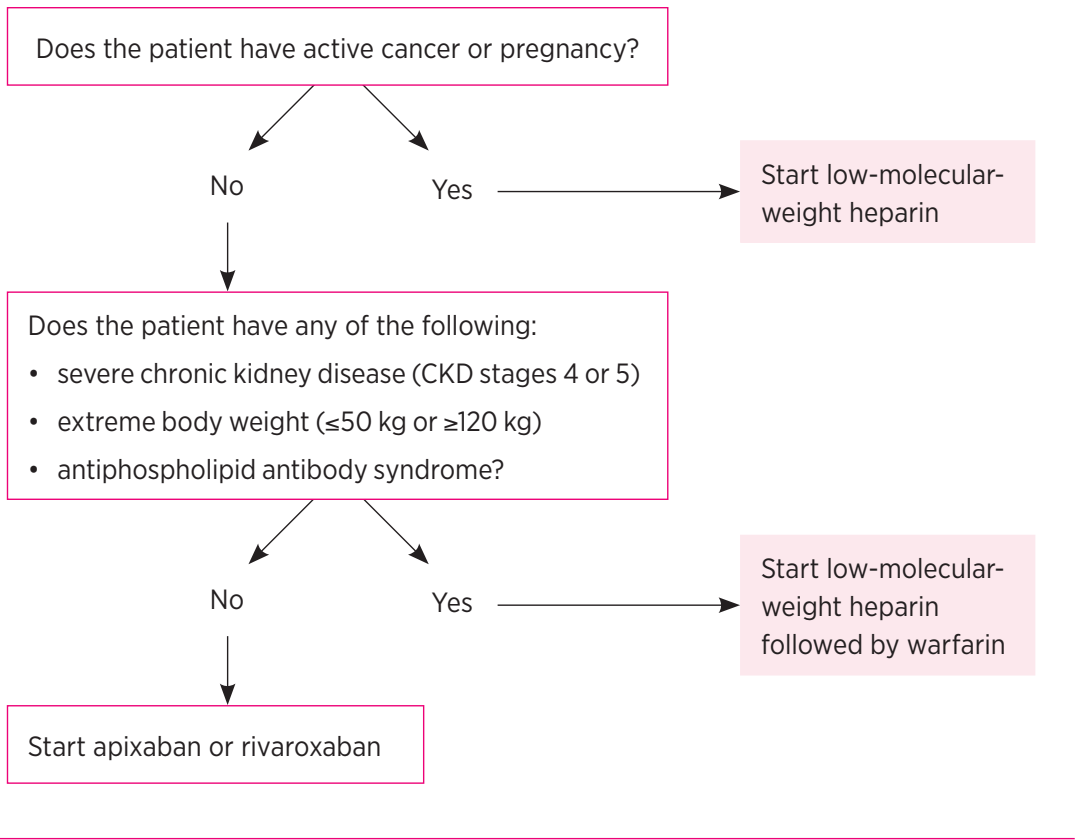

Patients with venous thromboembolism associated with active malignancy should also be treated with a low-molecular-weight heparin as this is more effective than warfarin in preventing recurrent venous thromboembolism. ${ }^{12}$ There is emerging evidence that a direct oral anticoagulant may be a reasonable alternative in some cancers. ${ }^{13,14}$ However, this is not yet routine clinical practice and should only be considered in consultation with a specialist.

\section{Duration of initial treatment}

The duration of initial treatment is determined by the location of the thrombosis.

\section{Proximal deep vein thrombosis and pulmonary embolism}

Anticoagulation is indicated for patients with proximal deep vein thrombosis and pulmonary embolism as it reduces the development of pulmonary embolism and extension of deep vein thrombosis. It also reduces the mortality associated with pulmonary embolism. ${ }^{3}$

Anticoagulation is required for at least three months. A shorter duration (e.g. 4-6 weeks) is associated with higher rates of recurrence. 15,16

\section{Distal deep vein thrombosis}

Distal deep vein thrombosis is confined to veins distal to the popliteal vein, including the tibial and peroneal veins and the calf muscle veins (soleal and gastrocnemius). It has a lower risk of extension and of associated pulmonary embolism than proximal deep vein thrombosis. ${ }^{17,18}$

Clinical trials of anticoagulation for distal deep vein thrombosis have discordant results. Some suggest six weeks to three months of anticoagulation is needed while others question the need for anticoagulation at all. ${ }^{19-22} \mathrm{~A}$ common practice is to treat with therapeutic anticoagulation for six weeks to three months for symptomatic patients with a low bleeding risk and isolated distal deep vein thrombosis. This is reflected in new Australasian guidelines. ${ }^{23}$ If the bleeding risk is considered high (e.g. active bleeding, thrombocytopenia with platelets $<50 \times 10^{9} / \mathrm{L}$ ), surveillance ultrasound (at least two ultrasounds over two weeks) is a reasonable alternative. If ultrasound shows an extension of the deep vein thrombosis, anticoagulation should be given.

\section{Extended anticoagulation for unprovoked venous thromboembolism}

Venous thromboembolism often recurs. Ongoing anticoagulation reduces recurrence by about $80 \%$. However, it is required long term and is associated with bleeding and inconvenience. An assessment of the risks of recurrence and bleeding is required to determine if extended anticoagulation is indicated. The most important predictors of recurrence include proximal 
deep vein thrombosis or pulmonary embolism, a history of previous venous thromboembolism and male sex ${ }^{16,24}$ (Table 2). The most common thrombophilias heterozygous factor $\mathrm{V}$ Leiden and prothrombin gene mutations - have little effect on recurrence and do not guide the duration of anticoagulation. ${ }^{25}$

Anticoagulation is stopped after three months if the risk of recurrence is low (e.g. surgically provoked venous thromboembolism, distal deep vein thrombosis). It is continued indefinitely if the risk is high (e.g. previous venous thromboembolism, active cancer, antiphospholipid antibody syndrome). However, in many cases there is an intermediate risk of recurrence. In these patients, ongoing low-intensity anticoagulation is safe and effective. Low doses of apixaban ( $2.5 \mathrm{mg}$ twice daily) and rivaroxaban (10 mg daily) are as effective in preventing recurrence as full doses and have a favourable bleeding profile. ${ }^{26,27}$ Major bleeding in these patients using lowdose anticoagulation is similar to those not receiving anticoagulants. Strong consideration should be given to indefinite low-intensity anticoagulation for patients at intermediate risk of recurrence (e.g. non-surgical or unprovoked venous thromboembolism, especially in males). Patient preference is extremely important in this decision making. ${ }^{26,27}$

In unprovoked venous thromboembolism, low-dose aspirin reduces rates of recurrence, ${ }^{28}$ but to a much lower extent than low-dose rivaroxaban or apixaban. Aspirin is not recommended for extended treatment of venous thromboembolism, but it may be considered if the decision has been made to stop anticoagulation and a patient requires aspirin for another indication.

Predictors of bleeding include previous major bleeding during anticoagulation, thrombocytopenia and the presence of a lesion with a high bleeding risk (e.g. active peptic ulceration). These are uncommon and specialist advice should be sought if present.

\section{Laboratory testing}

Blood monitoring is not routinely required for direct oral anticoagulants due to their predictable pharmacokinetics. It is occasionally considered in circumstances such as preoperatively in patients with renal insufficiency, following an adverse event or to assess adherence. Testing includes the dilute thrombin time for dabigatran, or a chromogenic anti-Xa assay for rivaroxaban and apixaban. ${ }^{29}$

Direct oral anticoagulants may interfere with routine and special coagulation testing. Of note, lupus anticoagulant testing may be falsely positive and clot-based protein $\mathrm{C}$ and $\mathrm{S}$ testing may give spurious results. ${ }^{30}$ Discussion with a haematologist before ordering these tests is recommended.

\section{Conclusion}

Direct oral anticoagulants are the first-line treatment for both initial and extended treatment of venous thromboembolism in most patients. An initial three months of anticoagulation is usually indicated for acute venous thromboembolism. After this, the decision of whether or not to continue anticoagulation indefinitely is made based on the likelihood of recurrence and the patient's bleeding risk. The favourable efficacy and safety of low-dose rivaroxaban and apixaban has expanded the indications for indefinite therapy. However, no anticoagulant is without risk and ongoing reassessment of the benefits of therapy versus the risk of bleeding is essential. $<$

Harry Gibbs has received honoraria from Pfizer Australia and Bayer for attending advisory boards and for presenting at educational meetings.

Huyen Tran has participated in advisory board meetings for Bayer.

\section{Table 2 Risk factors for venous thromboembolism recurrence}

\begin{tabular}{lll}
\hline Category & Example & Recurrence rate at 12 months* \\
\hline Surgically provoked & Major surgery & Low (1\%) \\
Distal deep vein thrombosis & & Low (1-3\%) \\
Non-surgically provoked & Long-distance air travel, hospitalisation for & Intermediate (5\%) \\
& medical illness, oestrogen use & Intermediate (8-10\%) \\
\hline Unprovoked & No identified provoking factor & High (>10\%) \\
\hline Persistent risk factor(s) & Active cancer, inflammatory bowel disease, \\
& antiphospholipid antibody syndrome & High (15\%) \\
\hline
\end{tabular}

* 12-month recurrence rate without anticoagulant therapy, after an initial anticoagulant course of 3-6 months. 


\section{REFERENCES}

1. Heit JA. Epidemiology of venous thromboembolism. Nat Rev Cardiol 2015;12:464-74. https://doi.org/10.1038/ nrcardio.2015.83

2. Barritt DW, Jordan SC. Anticoagulant drugs in the treatment of pulmonary embolism. A controlled trial. Lancet 1960;275:1309-12. https://doi.org/10.1016/ S0140-6736(60)92299-6

3. Agnelli G, Becattini C. Acute pulmonary embolism. N Engl J Med 2010;363:266-74. https://doi.org/10.1056/ NEJMra090773

4. Bauersachs R, Berkowitz SD, Brenner B, Buller HR, Decousus H, Gallus AS, et al.; EINSTEIN Investigators. Oral rivaroxaban for symptomatic venous thromboembolism. N Engl J Med 2010;363:2499-510. https://doi.org/10.1056/ NEJMoa1007903

5. Büller HR, Prins MH, Lensin AW, Decousus H, Jacobson BF, Minar E, et al.; EINSTEIN-PE Investigators. Oral rivaroxaban for the treatment of symptomatic pulmonary embolism. N Engl J Med 2012;366:1287-97. https://doi.org/10.1056/ NEJMoa1113572

6. Schulman S, Kearon C, Kakkar AK, Mismetti P, Schellong S, Eriksson H, et al.; RE-COVER Study Group. Dabigatran versus warfarin in the treatment of acute venous thromboembolism. N Engl J Med 2009;361:2342-52. https://doi.org/10.1056/NEJMoa0906598

7. Agnelli G, Buller HR, Cohen A, Curto M, Gallus AS, Johnson M, et al.; AMPLIFY Investigators. Oral apixaban for the treatment of acute venous thromboembolism. N Engl J Med 2013;369:799-808. https://doi.org/10.1056/ NEJMoa1302507

8. Cardiovascular Expert Group. Venous thromboembolism: treatment. In eTG complete [Internet]. Melbourne: Therapeutic Guidelines Limited; 2018. www.tg.org.au [cited 2019 Jul 1].

9. Tran H, Joseph J, Young L, McRae S, Curnow J, Nandurkar H, et al.; Australasian Society of Thrombosis and Haemostasis. New oral anticoagulants: a practical guide on prescription, laboratory testing and peri-procedural/bleeding management. Intern Med J 2014;44:525-36. https://doi.org/ 10.1111/imj. 12448

10. Bortz $\mathrm{H}$, Corallo $\mathrm{CE}$, Tran $\mathrm{H}$. Increasing understanding regarding the risk of concomitant use of carbamazepine and direct oral anticoagulants. J Pharm Pract 2019;32:123-5. https://doi.org/10.1177/0897190018786837

11. Martin K, Beyer-Westendorf J, Davidson BL, Huisman MV, Sandset PM, Moll S. Use of the direct oral anticoagulants in obese patients: guidance from the SSC of the ISTH. J Thromb Haemost 2016;14:1308-13. https://doi.org/10.1111/ jth.13323

12. Lee AY, Levine MN, Baker RI, Bowden C, Kakkar AK, Prins M, et al.; Randomized Comparison of Low-MolecularWeight Heparin versus Oral Anticoagulant Therapy for the Prevention of Recurrent Venous Thromboembolism in Patients with Cancer (CLOT) Investigators. Low-molecularweight heparin versus a coumarin for the prevention of recurrent venous thromboembolism in patients with cancer. N Engl J Med 2003;349:146-53. https://doi.org/10.1056/ NEJMoa025313

13. Young AM, Marshall A, Thirlwall J, Chapman O, Lokare A, Hill C, et al. Comparison of an oral factor Xa inhibitor with low molecular weight heparin in patients with cancer with venous thromboembolism: results of a randomized trial (SELECT-D). J Clin Oncol 2018;36:2017-23. https://doi.org/ 10.1200/JCO.2018.78.8034

14. Raskob GE, van Es N, Verhamme P, Carrier M, Di Nisio M, Garcia D, et al.; Hokusai VTE Cancer Investigators. Edoxaban for the treatment of cancer-associated venous thromboembolism. N Engl J Med 2018:378:615-24. https://doi.org/10.1056/NEJMoa1711948

15. Kearon C, AkI EA, Comerota AJ, Prandoni P, Bounameaux H, Goldhaber SZ, et al. Antithrombotic therapy for VTE disease: antithrombotic therapy and prevention of thrombosis, 9th ed: American College of Chest Physicians Evidence-Based Clinical Practice Guidelines. Chest 2012;141:e419S-e496S. https://doi.org/10.1378/chest.11-2301
16. Kearon C, Akl EA, Ornelas J, Blaivas A, Jimenez D, Bounameaux $\mathrm{H}$, et al. Antithrombotic therapy for VTE disease: CHEST guideline and expert panel report. Chest 2016;149:315-52. https://doi.org/10.1016/ j.chest.2015.11.026

17. Garry J, Duke A, Labropoulos N. Systematic review of the complications following isolated calf deep vein thrombosis. Br J Surg 2016;103:789-96. https://doi.org/10.1002/bjs.10152

18. Robert-Ebadi H, Righini M. Should we diagnose and treat distal deep vein thrombosis? Hematology (Am Soc Hematol Educ Program) 2017;2017:231-6. https://doi.org/10.1182/ asheducation-2017.1.231

19. Righini M, Galanaud JP, Guenneguez H, Brisot D, Diard A Faisse $\mathrm{P}$, et al. Anticoagulant therapy for symptomatic calf deep vein thrombosis (CACTUS): a randomised, double-blind, placebo-controlled trial. Lancet Haematol 2016:3:e556-62. https://doi.org/10.1016/S2352-3026(16)30131-4

20. Schwarz T, Buschmann L, Beyer J, Halbritter K, Rastan A, Schellong S. Therapy of isolated calf muscle vein thrombosis: a randomized, controlled study. J Vasc Surg 2010;52:1246-50. https://doi.org/10.1016/j.jvs.2010.05.094

21. Pinede L, Ninet J, Duhaut $P$, Chabaud $S$, Demolombe-Rague S, Durieu I, et al.; Investigators of the "Durée Optimale du Traitement AntiVitamines K" (DOTAVK) Study. Comparison of 3 and 6 months of oral anticoagulant therapy after a first episode of proximal deep vein thrombosis or pulmonary embolism and comparison of 6 and 12 weeks of therapy after isolated calf deep vein thrombosis. Circulation 2001;103:2453-60. https://doi.org/ 10.1161/01.CIR.103.20.2453

22. Lagerstedt $\mathrm{Cl}$, Olsson CG, Fagher BO, Oqvist BW, Albrechtsson U. Need for long-term anticoagulant treatment in symptomatic calf-vein thrombosis. Lancet 1985;326:515-8. https://doi.org/10.1016/S0140-6736(85)90459-3

23. Tran HA, Gibbs H, Merriman E, Curnow JL, Young L, Bennett A, et al. New guidelines from the Thrombosis and Haemostasis Society of Australia and New Zealand for the diagnosis and management of venous thromboembolism. Med J Aust 2019;210:227-35. https://doi.org/10.5694/ mja2.50004

24. Iorio A, Kearon C, Filippucci E, Marcucci M, Macura A Pengo V, et al. Risk of recurrence after a first episode of symptomatic venous thromboembolism provoked by a transient risk factor: a systematic review. Arch Intern Med 2010;170:1710-6. https://doi.org/10.1001/ archinternmed.2010.367

25. Stevens SM, Woller SC, Bauer KA, Kasthuri R, Cushman $M$, Streiff $M$, et al. Guidance for the evaluation and treatment of hereditary and acquired thrombophilia. J Thromb Thrombolysis 2016;41:154-64. https://doi.org/ 10.1007/s11239-015-1316-1

26. Agnelli G, Buller HR, Cohen A, Curto M, Gallus AS, Johnson M, et al.; AMPLIFY-EXT Investigators. Apixaban for extended treatment of venous thromboembolism. N Engl J Med 2013;368:699-708. https://doi.org/10.1056/ NEJMoa1207541

27. Weitz JI, Lensing AW, Prins MH, Bauersachs R, Beyer-Westendorf J, Bounameaux H, et al.; EINSTEIN $\mathrm{CHOICE}$ Investigators. Rivaroxaban or aspirin for extended treatment of venous thromboembolism. N Engl J Med 2017;376:1211-22. https://doi.org/10.1056/NEJMoa1700518

28. Becattini C, Agnelli G, Schenone A, Eichinger S, Bucherini E, Silingardi M, et al.; WARFASA Investigators. Aspirin for preventing the recurrence of venous thromboembolism. N Engl J Med 2012;366:1959-67. https://doi.org/10.1056/ NEJMoa1114238

29. Dale BJ, Chan NC, Eikelboom JW. Laboratory measurement of the direct oral anticoagulants. Br J Haematol 2016;172:315-36. https://doi.org/10.1111/bjh.13810

30. Adcock DM, Gosselin R. Direct oral anticoagulants (DOACs) in the laboratory: 2015 review. Thromb Res 2015;136:7-12. https://doi.org/10.1016/j.thromres.2015.05.001 